\title{
Investigation of Relationship between Learning University Dimensions and Intrapreneurship
}

Sana Safari

Assistant professor, Department of Educational Sciences, Payame Noor University, Tehran, Iran

Seyyed Mohsen Azizi

PhDs, Department of Educational Sciences, Payame Noor University, Tehran, Iran

Arash Ziapour

Kermanshah University of Medical Sciences, Kermanshah, Iran *Corresponding author: arash.ziapour@kums.ac.ir

\section{Doi:10.5901/mjss.2016.v7n3s2p27}

Abstract

The aim of this paper is investigate the Relationship between learning university dimensions and Intrapreneurship. The method of this research is descriptive - correlation. Targeted populations of the research were Razi University employees in the city of Kermanshah (Iran). 120 employees were selected as random sampling. Data collected using two questionnaires: learning university, and Intrapreneurship questionnaire. The questionnaires reliability was supported based on Cranach's alpha. Reliability coefficients were 0.87 (learning university) and 0.88 (Intrapreneurship) respectively. Questionnaire validity confirmed by specialist view of point. The present study tests such as, mean, standard deviation and inferential statistics, regression, and Pearson correlation coefficient was used, using Spss19, research hypotheses were tested. The results indicate that the correlation coefficient between learning university and Intrapreneurship employee $(p \leq 0.01)$ is meaningful and positive. The regression result showed the meaningful impact of the learning university dimensions on Intrapreneurship $(R 2=0.594)$. According to the findings, it can be suggested that the existence of Learning in organization can result in the improvement and development of Intrapreneurship.

Keywords: learning university, Intrapreneurship, employees

\section{Introduction}

In the third millennium, organizations have become more complex than what they have previously been. In the meantime, learning, proper reactions, adaptation to the vast changes that they are faced with every day are of prominent significance. In an era known as the information age, universities have entered a new field characterized by competition, quality, long-term learning in different parts, including staff, students, and faculty members. Two pivotal issues entitled "Training University" and "Research University" was raised by Marton \& Bowden (1998) concerning the higher education. In fact, the higher education was named the "Learning University" according to Peter Senge's theory (Bowden \& Marton, 1998).

The idea of learning organization in the context of management theory was developed by Argyris and Schön (1978) and made popular by Senge (Coppieters, 2005). According to Marsick \& Watkins (2004), a learning organization is the one engaged in acquiring and sharing knowledge used in the event of coping with the environmental changes and developments. From their points of view, learning is created in three levels of individual, group and organization to influence the organization's abilities, and more to the point, the three basic features that are advocated in this perspective are the presences of a system supporting the continuous learning, learning that leads to knowledge production, and directing the gained knowledge at improving performance.

In general, the overall objective of learning in organizations is to create a capability based on human resources, which is in line with one of the basic principles of human resources management, i.e., there should be investments of workforce so that the required human capital in organizations is developed towards increasing their knowledge supplies and skills. 
In line with this discussion, the Intrapreneurship is one of the factors that play an important role in maintaining competitiveness and increasing quality in today's organizations. Nowadays, entrepreneurship and developing entrepreneur's organizations lead to economic development (Safari et al, 2014). An entrepreneurial organization is the one with learning, innovation and opportunism embedded in its heart. Moreover, the Intrapreneurship in universities refers to the fact that staff should be also involved in the entrepreneurial activities along with students and faculty members (Ropke, 1998).

Moving towards an entrepreneurial organization requires the existence of a proper organizational culture, as a facilitator, through which the members' behaviors at different levels are formed and can influence the organization by creating changes towards a specific goal. In general, an organization is considered entrepreneurial when it can create, learn and influence its environment (Garsia, 2006).

In line with this Research the results showed Shams et al (2015) that learning organization indirectly impacts on organizational performance through organizational learning.

The most important finding of the Hernaus et al (2008) study is the empirical evidence about existence of strong, statistically significant, positive relationship between organizational learning and organizational performance.

Chang and Lee (2007) and Erdem et al (2014) showed there were significant differences between learning organization and job satisfaction.

Pak et al (2008) indicated that organizational learning is equally important in explaining organizational commitment, job satisfaction and work performance.

Joo (2009) concluded that organizational learning culture, proactive personality, and perceived job complexity accounted for $44 \%$ and $54 \%$ of the variances in organizational commitment and intrinsic motivation, respectively.

Universities are generally the most important factors in knowledge production, expanding the boundaries of knowledge and also increasing the strength and competitiveness of societies. The Intrapreneurship is one of the approaches that can play vital roles in the development and improvement of these capabilities. Therefore, the factors that can affect the Intrapreneurship should be given careful consideration.

So, the objective of the study was to determine the relationship between the learning university and Intrapreneurship among employee.

\section{Research Hypothesis}

1. There is significant Relationship between Learning University and Intrapreneurship.

2. Learning university had an effect on Intrepreneurship.

\section{Research Methods}

The quantitative survey research method was used to investigate Relationship between learning university dimensions and Intrapreneurship. The model of the research is a descriptive correlation survey design. Targeted populations of the research were all the employees of Razi University in the city of Kermanshah (Iran) in academic year 2014-2015. 120 employees were selected as Random sampling. For data collection, Rodrigs's Intrapreneurship questionnaire (2010) and a Learning University questionnaire based of Marsic and Watkinz's learning organization (2004) were used.

The learning university questionnaire consisted of 43 questions with Likert Scaling (1= Extremely Negative ... and 5= Extremely Positive) and examined 3 factors: Individual Learning, Team Learning and Organization Learning.

In studies Yang et al (2004) the coefficient range for each of the subscales was between 0.83 and 0.93 . The reliability coefficient of this questionnaire in the present study is (Cronbach's Alpha Coefficient) 0.87 .

The Intrapreneurship questionnaire consisted of 28 questions with Likert Scaling (1= strongly disagree... and 5= strongly agree) and examined 6 factors: Task Innovation, Entrepreneurial Employee, Structural Flexibility, Incentive Policy, Entrepreneurial Leadership, Entrepreneurial Cultural. The reliability coefficient of this questionnaire in the present study is (Cronbach's Alpha Coefficient) 0.88.

Data were analyzed through Mean, Standard devotion, Pearson correlation test, and regression analysis. Also, the 19th version of SPSS-19 software was used for data analysis. 
4. Data Analysis Result

Table 1. Profile of Respondents Based on Gender

\begin{tabular}{lcc}
\hline Gender & Amount & Percent \\
\hline Male & 73 & 60.8 \\
Female & 47 & 39.2 \\
Total & 120 & 100.00 \\
\hline
\end{tabular}

Demographic characteristics of respondent's shows, out of the 120 participants in the present study, 73 individuals (60.8\%) were Male and 47 individuals (39.2\%) were Female.

Table 2 illustrates the Mean and Standard Devotion of the Learning University and Intrapreneurship.

Table 2. Basic descriptive statistics for perceived learning University and Intrapreneurship

\begin{tabular}{llccc}
\hline & Dimensions & N & M & SD \\
\hline Learning University & Individual Learning & 120 & 28.80 & 7.46 \\
& Team Learning & 120 & 27.33 & 5.39 \\
& Organization Learning & 120 & 27.30 & 5.57 \\
& Learning University & 120 & 83.43 & 16.48 \\
Intrapreneurship & 120 & 16.36 & 2.82 \\
& Task Innovation & 120 & 17.01 & 2.57 \\
& Intrapreneurial Employee & 120 & 14.15 & 2.16 \\
& Structural Flexibility & 120 & 15.26 & 2.10 \\
& Incentive Policy & 120 & 14.39 & 2.69 \\
& Intrapreneurial Leadership & 120 & 13.60 & 3.25 \\
& Intrapreneurial Cultural & 120 & 90.80 & 12.23 \\
\hline
\end{tabular}

Table2 present the means and standard deviations of learning University and Intrapreneurship. The mean total learning university score was $\mathrm{M}=83.43, \mathrm{SD}=16.48$. In the subscale of learning University, Individual Learning was the $\mathrm{M}=28.80$ $S D=7.46$, Team Learning was the $M=27.33 \quad S D=5.39$, Organization Learning was the $M=27.30 S D=5.57$.

The mean total Intrapreneurship score was $M=90.80, S D=12.23$. In the subscale of Intrapreneurship, Task Innovation was the $M=16.36 \mathrm{SD}=2.82$, Intrapreneurship Employee was the $M=17.01 \mathrm{SD}=2.57$, Structural Flexibility was the $M=14.15 S D=2.16$, Incentive Policy was the $M=15.26 S D=2.10$, Intrapreneurship Leadership was the $M=$ 14.39 SD= 2.69, Intrapreneurship Cultural was the $M=13.60 \mathrm{SD}=3.25$.

Table 3 illustrates the relationship between Learning University dimension and Intrapreneurship.

Table 3. Person Correlations between Learning University dimension and Intrapreneurship

\begin{tabular}{llcccl}
\hline & 1 & 2 & 3 & 4 & 5 \\
\hline 1 Individual Learning & 1 & & & & \\
2 Team Learning & $0.456^{\star *}$ & 1 & & & \\
3 Organization Learning & $0.310^{\star *}$ & $0.864^{* *}$ & 1 & & \\
4 Learning University & $0.707^{\star *}$ & $0.859^{* *}$ & $0.865^{\star *}$ & 1 & \\
5 Intrapreneurship & $0.754^{* *}$ & $0.367^{* *}$ & $0.656^{\star *}$ & $0.558^{* *}$ & 1 \\
\hline
\end{tabular}

${ }^{*}$ Correlation is significant at the 0.01 level

The results of a Pearson's correlation analysis revealed that learning University was significantly correlated with their Intrapreneurship $(r=0.558, p \leq 0.01)$.

The coefficients between dimension Individual Learning $(r=0.754)$, dimension Team Learning $(r=0.367)$ and dimension Organization Learning ( $r=0.656)$ have most strongly positive related with Intrapreneurship $(p \leq 0.01)$. 
Table 4. Summary of regression analysis conducted to predict of variance of Intrapreneurship

Summary of regression analysis, Influence learning university dimensions on Intrapreneurship

\begin{tabular}{lcccccc}
\hline & \multicolumn{3}{c}{ Unstandardized coefficients standardized coefficients } & \multirow{2}{*}{$\mathrm{t}$} & \multirow{2}{*}{ R Square } & sig \\
\cline { 2 - 5 } Model & $\mathrm{B}$ & Std. Error & Btea & & 13.061 & \\
Constant & 1.311 & 0.100 & - & 0.000 \\
Individual Learning & 0.260 & 0.061 & 0.432 & 4.461 & 0.594 & 0.000 \\
Team Learning & 0.115 & 0.026 & 0.302 & 4.421 & 0.000 \\
Organization Learning & 0.090 & 0.039 & 0.218 & 2.293 & 0.024 \\
\hline
\end{tabular}

According to Table 4, learning university had an effect on Intrepreneurship. Individual Learning (Beta=0.432), Team Learning (Beta=0.302) and Organization Learning (0.218) influenced the Intrepreneurship. The $\mathrm{R}^{2}$ value was 0.594 , showing that learning university dimensions had a $594 \%$ effect on Intrepreneurship $\left(R^{2}=0.594\right)$.

\section{Discussion and Conclusions}

The results demonstrated that there was a significant positive relationship between the learning university and Intrepreneurship. In addition, the learning university could predict the variance of the Intrepreneurship, namely, in general, the learning university beliefs could influence one's Intrepreneurship.

This findings was consistent with the results of studies Shams et al (2015), Chang and Lee (2007), Erdem et al (2014), Hernaus et al (2008), Park et al (2008) and Joo (2009).

Studies show that factors Organizational factors such as organizational structure, organizational culture, management support, reward systems and resource availability, influence to development of intrapreneurship (Ireland, et al., 2009; A. Zahra, et al., 2004) and organizational performance (Wood, et al., 2008; S. Zahra \& Garvis, 2000).

Franco \& Haase (2009), van Gelderen et al., (2005) reported that there is a significant relationship between learning behavior and contextual factors that affect entrepreneurial performance improvement (Alipour et al, 2011).

To create Intrapreneurship, a constructive organizational culture should be developed, in which staff are encouraged to work with others and perform duties and plans that will result in the satisfaction of their needs and growth. This type of culture confirms the normative or traditional beliefs related to progress, innovation, self-discovery, encouragement, altruism and dependency.

In this regard, Kefart and Marsic believe that individuals involved in learning organizations are encouraged to think based on new methods and use heuristic and productive skills on a regular basis to observe the relationships and feedback chains. The culture of a learning organization is a learning culture, and learning and creativity are encouraged at all levels of the organization under its umbrella (Gorbanizade, 2014).

To create learning and entrepreneurial organization, strategies should be created concerning the formulation of goals and policies of the organization in a way that their realizations require continuous staff's learning and training. In addition, the factors that should be considered in this regard include: reorganization of tasks and activities of the organization, assigning the liability for staff training and development to managers specialized in the field of human resources, creating effective communication between any decision-making relating to the recruitment and staff administration, training, employment status, individual and organizational capabilities, performing the continuous needs assessment to identify the staff's training needs, adoption of some supportive and incentive mechanisms and the establishment of a swift feedback system to fix the staff's work-related shortcomings, providing correct information to perform modifications, creating the appropriate groundwork for staff's participation in the organizational decision-makings, and paying attention to the staff's values and needs in individual, group and organizational levels (Niazazari, 2014).

Since entrepreneurship focuses on the production of new ideas, it can propel societies towards technological developments, change new knowledge into new products and services and result in the economic growth. Therefore, the realization of the dimensions of the Intrapreneurship, as a creative and innovative action in universities, can lead to the growth of organizations, identifying opportunities and attracting and securing the required resources. In addition, it causes the operational plans to be designed by providing creative solutions, and these plans are implemented while accepting the risk and tolerance of failures and mistakes, and the results will be delivered to the organization and beneficiaries in a timely and easy manner. Furthermore, learning is one of the most important factors in the formation of the Intrapreneurship.

So, given the complexities of today's world, organizations can adapt their plans to transformations and swift environmental changes to realize their organizational goals with the aim of survival and success. Moreover, expanding 
the boundaries of knowledge and environmental challenges doubles the importance of being a learning organization, being equipped with strategies and appropriate techniques.

\section{References}

Bowden J. Marton F. (1998). The University of Learning: Beyond Quality and Competence. London: Kogan.

Coppieters P. (2005). Turning schools into learning organizations. European Journal of Teacher Education, 28(2): 129-139.

Marsick V, Watkins K E. (2003). Demonstrating the value an organization's learning culture: The dimensions of the learning organization questionnaire". Advances in Developing Human Resources, 5: 132-151.

Ropke J. (1998). The Entrepreneurial University Innovation, Academic Knowledge Creation and Regional Development in a Globalization Economy, Department Economics, Phipipps-University Marburg, Germany.

Garsia V, V Llorens-Montes, F Verd À-Jover A. (2006). Antecedents and consequences of organizational innovation and organizational learning in entrepreneurship. Industrial Management and Data Systems, 106 (1): 21.

Zahra A, Hayton J, Salvato C. (2004). Entrepreneurship in Family vs. Non Family Firms: A Resource Based Analysis of the Effect of Organizational Culture. Entrepreneurship Theory and Practice, 28 (4): 363-381.

Ireland R, Covin J, Kuratko D. (2009). Conceptualizing corporate entrepreneurship strategy. Entrepreneurship Theory and Practice, 33 (1): $19-46$.

Zahra S, Garvis D. (2000). International corporate entrepreneurship and firm performance the moderating effect of international environmental hostility. Journal of business venturing, 15 (5-6): 469-492.

Wood C, Holt D, Reed T, Hudgens B. (2008). Perception of corporate entrepreneurship in air force organizations. Journal of small business and entrepreneurship, 21 (1): 35-45.

Shams G, Pardakhtchi M, Maleki H. (2015). A Case Study on the Impact of Learning Organization on Organizational Performance through the Mediating Effect of Organizational Learning. Quarterly journal of new thoughts on education. 10 (3):9-28

Chang S C, Lee M S. (2007). A study on relationship among leadership, organizational culture, the operation of learning organization and employees' job satisfaction. The Learning Organization. 14(2): 155-185.

Erdem M, IIGan A, İbrahim Uçar H. (2014). Relationship between Learning Organization and Job Satisfaction of Primary School Teachers. International Online Journal of Educational Sciences, 6 (1): 8-20.

Hernaus T, Skerlavaj M, Dimovski V. (2008). Relationship between Organizational Learning and Organizational Performance: The Case of Croatia. International Journal of Scholarly paper. Transformations in Business \& Economics. 7 (2): 1-19.

Pak OG, Raja Kasim RS, Uli J, Munap R (2008). The effect of organizational learning on job commitment, job satisfaction and work performance in Malaysia: a mediation analysis. The Eighth International Conference on Knowledge, Culture and Change in Organizations. Cambridge: Cambridge University

Joo BK. (2009). The effects of organizational learning culture, perceived job complexity, and proactive personality on organizational commitment and intrinsic motivation. Leadership Organize Stud. 16 (1):48-60.

Rodrigues G. (2010). Intrapreneurship in a Fast Growing Economy: A Study of the Emirates of Dubai. The Business Review, 15: 144151.

Nadi MA, Sajadian I. (2010). Factor structure, reliability, validity and standardization of scale, learning organization in University: Learning University. Journal of Educational Sciences. 3 (12): 121-142.

Yang B, K Watkins, V Marsick. (2004). the Construct of the Learning Organization: Dimensions, Measurement and Validation. Human Resource Development Quarterly, 15: 31-55.

AhmadPour M, Moghimi, SM. (2013). Entrepreneurship Foundation. Tehran: Publisher by Faraandish., p 218

NiazAzari K. (2001). Behavior and human relations in Educational organization in the Third Millennium. Tehran: Publisher by Farashenakhti Andishe.

Safari S, Ojaghi Mirkoohi N, Najafi Hezarjaribi H, Aslami M (2014). Investigating the Relationship between Solid Intelligence and Organizational Entrepreneurship among Payame Noor University Employees. Reef Resources Assessment and Management Technical Paper, 40 (5), 1, 220-223. 